\title{
Complications in neuroanesthesia
}

Editor: Hemanshu Prabhakar

Publisher: Elsevier Inc.

Edition: First

Location: San Diego, USA

Year of Publication: 2016

Price: 125 USD

ISBN: 978-0-12-804075-1

Pages: 473

In no other speciality of medicine does a complication have so much impact on the outcome as in neuroanaesthesia and neurosurgery. Beit herniation, airway-related complication, or post-operative visual loss, its consequences are far reaching. Regular neuroanaesthesia books, though make a mention of these complications, do not have a scope to cover them elaborately. The authors of this book have taken the task of compiling them in a systematic way. This book comprehensively covers all known complications that are likely to occur in day-to-day practice of neuroanaesthesia. Although it is a multi-authoured book, each chapter systematically covers description of the complication, its mechanism, its management and its prevention. This approach provides a comprehensive understanding to the reader of the action to be taken when faced with a particular complication in the perioperative period.

The book contains nine sections dealing with different complications and a tenth section which describes the illustrative cases. The first section deals with complications related to the brain. This section covers vividly the delayed emergence, brain swelling, seizures and various types of herniations in addition to other issues such as pneumocephalus. The second section deals with complications related to spinal cord. This section deals with post-operative paraplegia and quadriplegia, spinal shock and autonomic disturbances associated with spinal cord injury. The third section covers the cardiovascular complication associated with neurosurgical conditions such as electrocardiographic abnormalities, cerebral vasospasm, management of a haemodynamically unstable neurosurgical patient and cardiovascular complications associated with rupture of cerebral aneurysms and arteriovenous malformations. The fourth section discusses coagulopathy in connection with traumatic brain injury, acute ischemic stroke and intracranial haemorrhage. This section also extensively discusses the post-operative haematoma. The most common mostly preventable complications of hypoxia and hypercapnia and neurogenic pulmonary oedema are extensively discussed in the fifth section. Apart from a description of the adult and paediatric difficult airway, causes and management of intraoperative increased airway pressure form the subjects of the sixth section. Neurological conditions are associated with a number of fluid and electrolyte disturbances. All these are covered under the seventh section. The eighth section covers the management of postoperative pain, following spinal surgery and craniotomy, which are most neglected in practice. The ninth section deals with various miscellaneous issues, most important among them being post-operative nausea and vomiting, post-operative visual loss and post-operative cognitive dysfunction.

The most interesting part of the book is the last section that describes ten clinical scenarios which are commonly encountered in clinical practice. Not only is the clinical description very lucid but also the description of the management is very clear.

Overall, the book is a good compilation of the complications that a practitioner faces during routine clinical neuroanaesthesia practice and is worth being possessed by all the anaesthesiologists who practice neuroanaesthesia either on a regular basis or occasionally.

\section{Ganne S. Umamaheswara Rao}

Department of Neuroanaesthesia, National Institute of Mental Health and Neurosciences,

Bengaluru, Karnataka, India.

E-mail: gsuma123@yahoo.com

This is an open access article distributed under the terms of the Creative Commons Attribution-NonCommercial-ShareAlike 3.0 License, which allows others to remix, tweak, and build upon the work non-commercially, as long as the author is credited and the new creations are licensed under the identical terms.

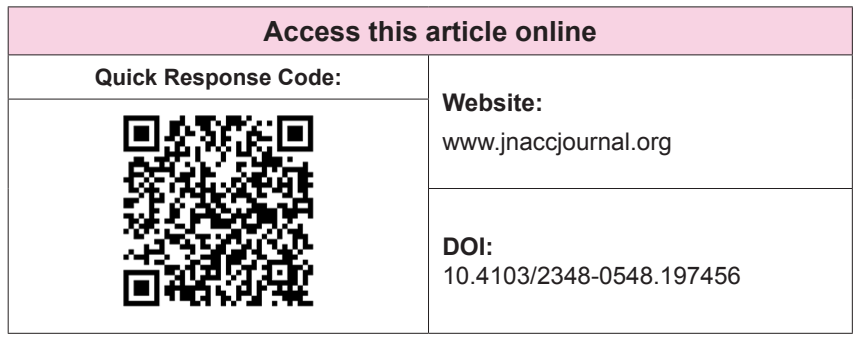

How to cite this article: Umamaheswara Rao GS. Complications in Neuroanesthesia. J Neuroanaesthesiol Crit Care 2017;4:67. 